\title{
Scanning electron microscopic study of Dacron degradation by ocular tissue extracts
}

\author{
SEIJI HAYASAKA, SEI-ICHI ISHIGURO, TAKASHI SHIONO, AND \\ KATSUYOSHI MIZUNO
}

From the Department of Ophthalmology, Tohoku University School of Medicine, Sendai, Japan

\begin{abstract}
SUMmARY A scanning electron microscopic study showed that the surface of Dacron thread became significantly roughened after treatment with bovine iris-ciliary body extracts. The Dacrondegrading factor in the extract was nondialysable, heat-labile, and active at an acidic $\mathrm{pH}$, suggesting that lysosomal enzymes may be a factor in this phenomenon. Bovine extracts from the iris, ciliary body, and sensory retina degraded the surface of Dacron most substantially, while the Dacron surface was moderately digested by extracts from the cornea and retinal pigment epithelium. Lenticular and choroidal extracts did not affect the Dacron surface. Possibly the factor that degrades Dacron may be different from that which affects nylon, and the Dacron suture may not be preferable for corneal surgery.
\end{abstract}

Peyman and co-workers ${ }^{12}$ demonstrated the feasibility of fixating a posterior chamber lens with Dacron fibres. However, intraocular degradation of Dacron has not been evaluated yet. We previously examined nylon degradation and found that the surface of the nylon thread was roughened after treatment with bovine ocular tissue extracts. ${ }^{3}$ We therefore examined whether Dacron thread treated in vitro with bovine ocular tissues is degraded or not.

\section{Materials and methods}

PREPARATION OF BOVINE OCULAR TISSUE EXTRACT

The extracts were prepared in the same way as described previously.' Briefly, the bovine ocular tissues were dissected in ice-cold $20 \mathrm{mM}$ potassium phosphate buffer ( $\mathrm{pH}$ 6.8), minced, and then homogenised in a blender. Each homogenate from the iris, ciliary body, neural retina, retinal pigment epithelium, choroid, cornea, and lens was centrifuged at $20000 \mathrm{~g}$ for $20 \mathrm{~min}$ to obtain a supernatant. Solid ammonium sulphate was added to the supernatant until $60 \%$ saturation was obtained (390 g/litre). The precipitate was collected by centrifugation, dissolved

Correspondence to S. Hayasaka, MD. Department of Ophthalmology, Tohoku University School of Medicine. Sendai. Miyagi 980, Japan. in a small amount of the same buffer, and dialysed overnight against the same buffer. The nondialysable fraction was used as the extract. The protein concentration in each extract was adjusted to $40 \mathrm{mg} / \mathrm{ml}$. Protein content was determined by the method of Lowry and associates. ${ }^{4}$

\section{TREATMENT OF DACRON IN VITRO}

The reaction mixture used to observe changes in Dacron usually consists of bovine ocular tissue extract $(12.5 \mathrm{mg}$ of protein) and $0.1 \mathrm{ml}$ of $500 \mathrm{mM}$ Trisacetate buffer ( $\mathrm{pH} \mathrm{5.2)}$ in a total volume of $0.5 \mathrm{ml}$. The 5-0 Dacron thread, $10 \mathrm{~mm}$ in length (Alcon, USA), was soaked in the mixture and incubated at $37^{\circ} \mathrm{C}$ for 12 to 18 hours with constant shaking. The incubation mixture was renewed every 6 hours. The $\mathrm{pH}$ change in the mixture, determined before and after incubation, was negligible. The treated Dacron was washed several times in $10 \mathrm{mM}$ potassium phosphate buffer $(\mathrm{pH} \mathrm{7.5)}$ until it became protein-free. The Dacron was then washed with distilled water and dried in vacuo.

\section{ELECTRON MICROSCOPY}

The Dacron was coated with gold and examined by scanning electron microscopy. We performed 3 separate experiments in vitro, starting from different sources, and selected the most representative picture of each Dacron thread. 


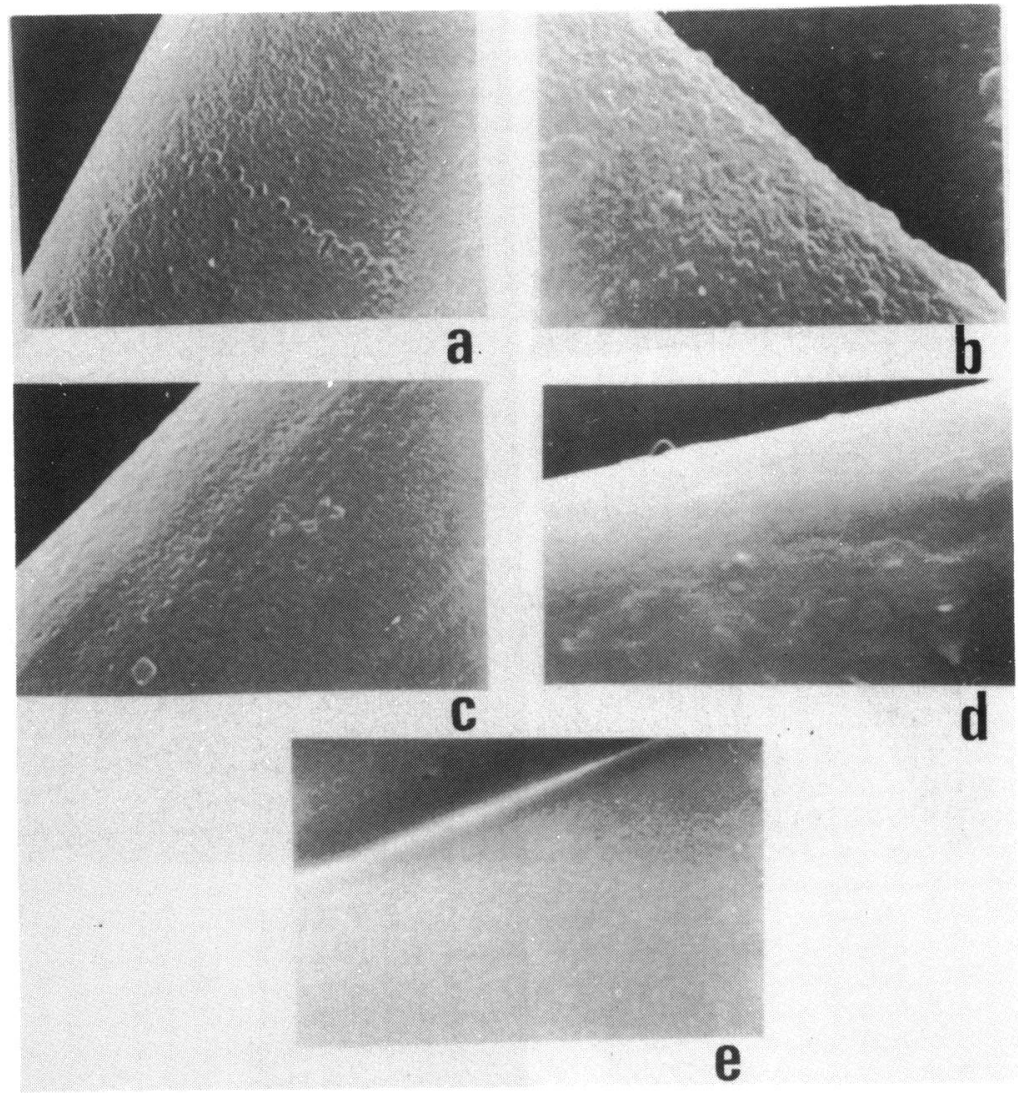

Fig. 1 Surface of 5-0 Dacron treated in vitro with bovine irisciliary body extract $(\times 8000)$. (a) Dacron before incubation has smooth surface with a little roughness. (b) Dacron treated at $37^{\circ} \mathrm{C}$ for 12 hours at $\mathrm{pH} 5 \cdot 2$; the extract is $12.5 \mathrm{mg}$ of protein per 0.5 $\mathrm{ml}$. Roughened surface by erosive action is evident. (c) Dacron treated with the extract, which was preheated at $90^{\circ} \mathrm{C}$ for 5 minutes at $37^{\circ} \mathrm{C}$ for 24 hours at $\mathrm{pH} 5 \cdot 2$, has an unaltered smooth surface.

(d) Dacron treated at $4^{\circ} \mathrm{C}$ for 24 hours at pH 5.2 with the extract shows a smooth surface. (e) The iris-ciliary body extract was preincubated at $37^{\circ} \mathrm{C}$ for 6 hours at pH 5.2 without soaking the Dacron thread. After the preincubation the Dacron was soaked in the extract and incubated; the surface of the Dacron is smooth.

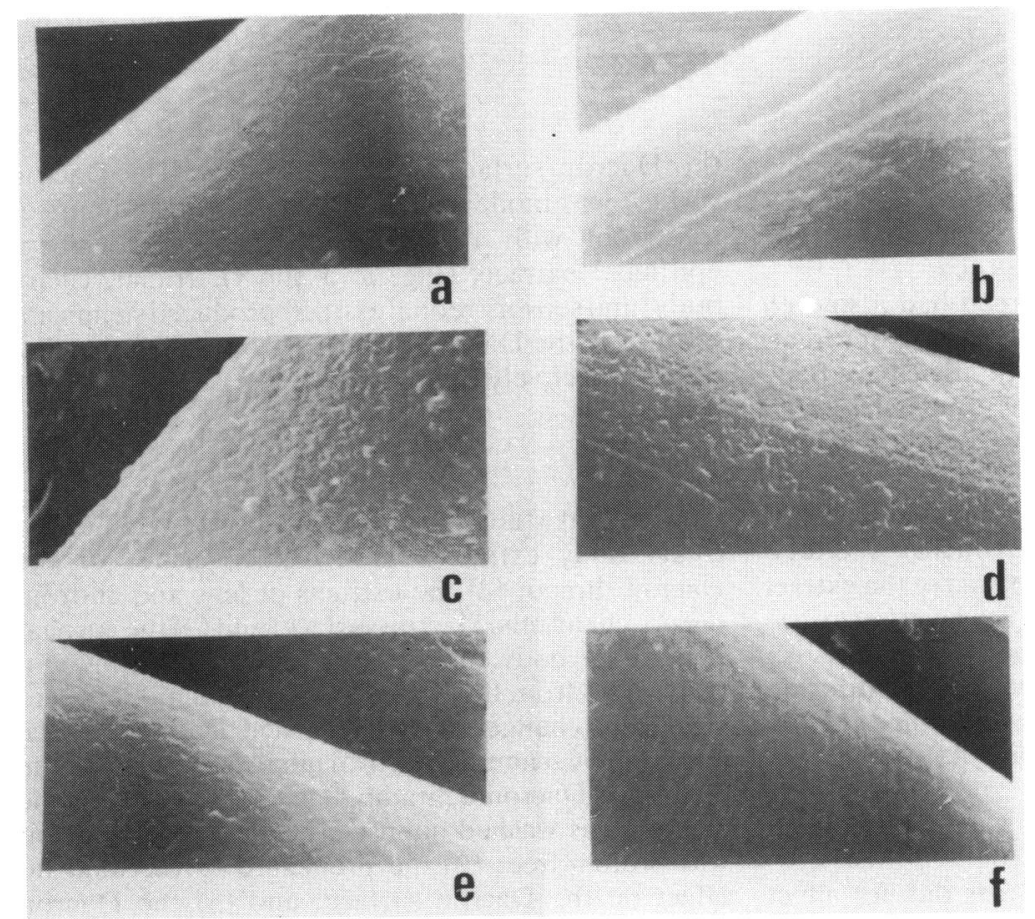

Fig. 2 Effect of $p H$ on the degradation of Dacron by the irisciliary body extract. The Dacron was treated at $37^{\circ} \mathrm{C}$ for 12 hours at various $\mathrm{pH}$ levels; $150 \mathrm{mM}$ Trisacetate buffer was used $(\times 8000)$.
(a) $p H 4 \cdot 3$. (b) $p H 4 \cdot 6$.
(c) $p H 5 \cdot 2$. (d) $p H 5 \cdot 6$.
(e) $\mathrm{pH} 5 \cdot 8$. (f) $\mathrm{pH} 6 \cdot 7$. 


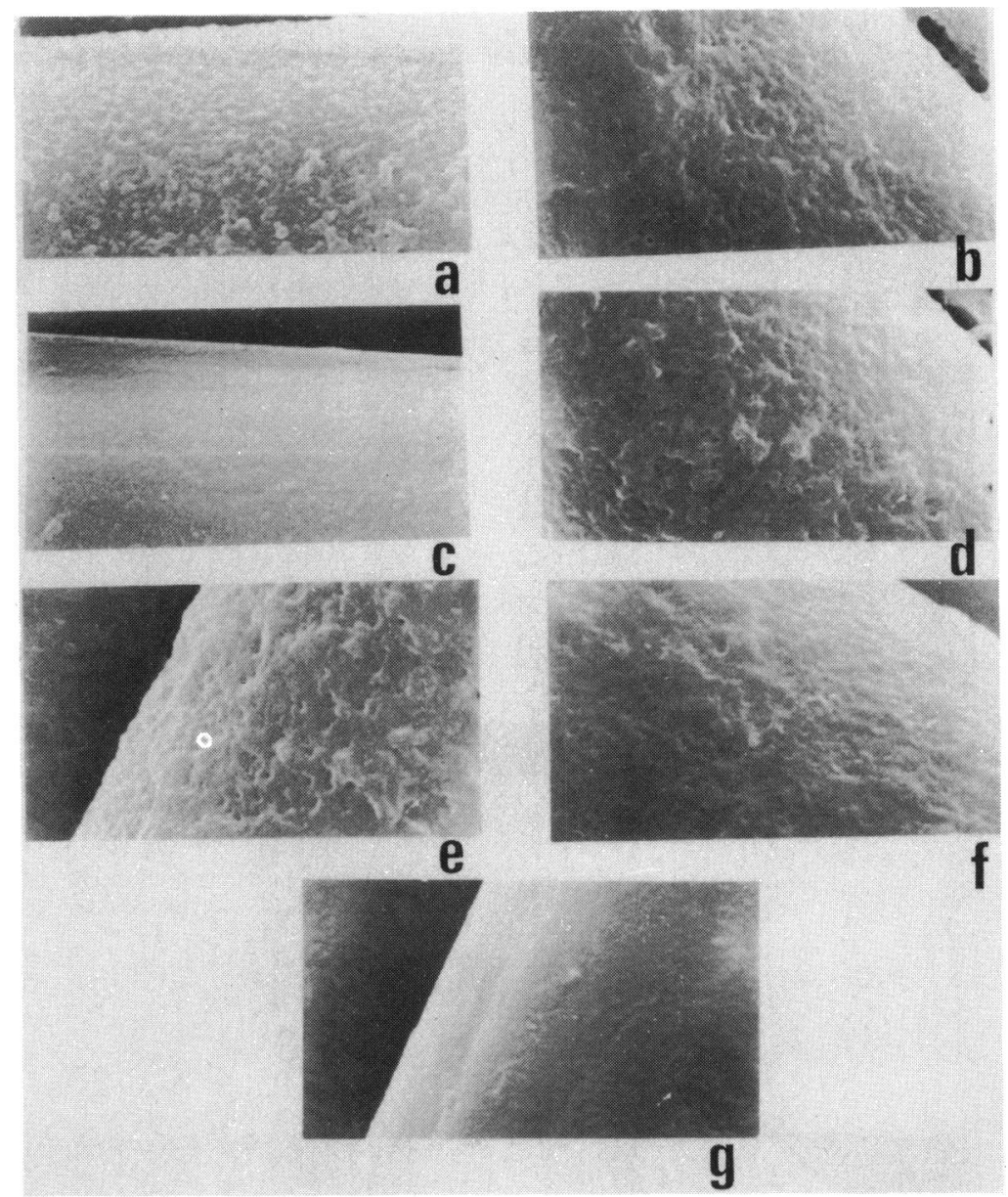

Fig. 3 The Dacron surface was treated in vitro with bovine ocular tissue extracts. The 5-0 Dacron was incubated at $37^{\circ} \mathrm{C}$ for 18 hours at pH 5.2 with the extracts $(12.5 \mathrm{mg}$ of protein per $0.5 \mathrm{ml})(\times 8000)$.
(a) Cornea. (b) Iris. (c) Lens.
(d) Ciliary body. (e) Sensory retina.
(f) Retinal pigment epithelium.
(g) Choroid.

\section{Results}

DACRON SURFACE TREATED IN VITRO WITH BOVINE IRIS-CILIARY BODY EXTRACT

Before treatment the Dacron thread had a smooth surface with a little roughness (Fig. 1, a). After treatment at $37^{\circ} \mathrm{C}$ for 12 hours with the iris-ciliary body extract the Dacron surface was roughened and irregular (Fig. 1, b). The extract pretreated with heat did not change the Dacron surface (Fig. 1, c), nor was it affected after treatment at $4^{\circ} \mathrm{C}$ (Fig. 1, d). After incubation of the iris-ciliary body extract at $37^{\circ} \mathrm{C}$ for 6 hours at $\mathrm{pH} 5 \cdot 2$ the Dacron was soaked in the extract and incubated at $4^{\circ} \mathrm{C}$ for 24 hours. The Dacron surface remained unaltered after this procedure (Fig. 1, e). The degrading effect of the iris-ciliary body extract on the Dacron surface occurred at wide ranges of $\mathrm{pH}$ $(4 \cdot 3$ to $6 \cdot 7$ ) but was most marked at $5 \cdot 2$ (Fig. 2 ).

DACRON SURFACE TREATED IN VITRO WITH BOVINE OCULAR TISSUE EXTRACT

The lenticular and choroidal extracts did not affect the Dacron surface (Fig. 3, c and g). The Dacron surface was moderately roughened after 18 hours of treatment with the corneal and retinal pigment epithelial extracts (Fig. 3, a and f). Iridial, ciliary body, and sensory retinal extracts produced significant erosion of the Dacron surface after 18 hours' incubation, respectively (Fig. 3, b, d, and e).

\section{Discussion}

Our present study showed that (1) the bovine irisciliary body extract degraded the surface of the Dacron thread; (2) the extracts of lens and choroid did not change the Dacron surface; and (3) the cornea. iris, ciliary body, neuroretina, and retinal pigment epithelium from the bovine eyes caused moderate to significant changes. The roughened Dacron surface observed by scanning electron microscopy may be the result of a Dacron-degrading factor, because, (1) the Dacron was washed intensively in the buffer until it was protein-free; $(2)$ the preheated extract had no effect on the Dacron surface; and (3) the Dacron 
incubated at $4^{\circ} \mathrm{C}$ for 24 hours with the preincubated extract was unaltered. These facts exclude the possibility of debris deposited on the Dacron surface, suggesting that the action of the extract accounts for the Dacron degradation. In addition, the Dacron-degrading factor was nondialysable, heat-labile, and active at an acidic $\mathrm{pH}$. Subsequently a lysosomal enzyme may be partially concerned in this phenomenon. Dacron is a commercial name for polyethylene terephthalates, whose chemical formula is shown in Fig. 4.

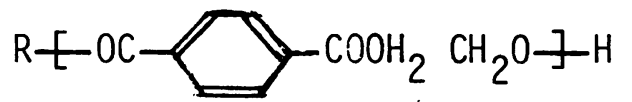

Fig. 4 Chemical formula of Dacron.

The covalent bonds of $-\mathrm{COO} \mathrm{CH}_{2} \mathrm{CH}_{2}-$ have a tendency to be hydrolysed.

Dacron is said to be more resistant to in vivo degradation than nylon, but its superiority is not conclusive. ${ }^{5}$ However, results of our present and previous study ${ }^{3}$ pointed out the differences in degradation between nylon and Dacron: (1) nylon degradation by iris-ciliary body extract was most marked at $\mathrm{pH} 5 \cdot 8$, while Dacron degradation was most pronounced at $\mathrm{pH} 5 \cdot 2 ;(2)$ the corneal extract degraded the Dacron but did not affect the nylon; and (3) the choroidal extract degraded the nylon but did not affect the Dacron. These findings suggest that the degrading factor of nylon may be different from that of Dacron. Because the Dacron suture is now considered a late-degrading suture, its use is not suitable in some corneal operations.

\section{References}

1 Peyman GA. Nyberg M. Experimental evaluation of a posterior chamber lens fixed with Dacron. Ophthalmic Surg 1979; 10: 64-8.

2 Peyman GA, Koziol J, Kaiserman R. Iris tissue reaction to Dacron and silk in primates: evaluation for intraocular lens fixation. Ophthalmic Surg 1979; 10: 69-75.

3 Hayasaka S, Ishiguro S, Shiono T, Okabe H. Mizuno K. A scanning electron microscopic study of nylon degradation by ocular tissue extracts. Am J Ophthalmol 1982; 93: 111-7.

4 Lowry OH, Rosebrough NJ, Farr AL, Randall RJ. Protein measurement with the Folin phenol reagent. J Biol Chem 1951; 193: $265-75$.

5 Jaffe ND. Galin MA. Hirschman H. Clayman HM. Molecular basis of implant materials. In Jaffe NS, Galin MA. Hirschman H, Clayman HM. eds. Pseudophakos. St Louis: Mosby, 1978: 6-25. 